\title{
A Novel Gene Conferring Citrus Tristeza Virus Resistance in Citrus maxima (Burm.) Merrill
}

\author{
D.Q. Fang and M.L. Roose ${ }^{1}$ \\ Department of Botany and Plant Sciences, University of California, Riverside, \\ CA 92521
}

Additional index words. Rutaceae, molecular markers

\begin{abstract}
Chandler' pummelo [Citrus maxima (Burm.) Merrill] was found to be citrus tristeza virus (CTV)-resistant. The inheritance of this resistance in 84 progeny of two crosses derived from 'Chandler' pummelo and trifoliate orange [Poncirus trifoliata (L.) Raf.] was controlled by a single dominant gene designated $C t v 2$. Progeny analysis of four molecular markers closely linked to the $C t v$ gene, which confers resistance to CTV in trifoliate orange, demonstrated that $C t v 2$ was an independently assorting gene from $C t v$.
\end{abstract}

Citrus tristeza virus (CTV), the most severe viral disease of citrus in the world, causes rapid decline and death of trees grafted on sour orange (Citrus aurantium L.) rootstocks, and stem pitting of grapefruit (C. paradisi Macf.) and sweet orange [C. sinensis (L.) Osbeck] trees regardless of rootstock (Garnsey et al., 1987). Since its outbreak in the 1930s, CTV has caused the death of more than 60 million citrus trees around the world (Bar-Joseph et al., 1989; Roistacher et al., 1991). Strict quarantine regulations and removal of CTV-infected trees from orchards have greatly diminished the damage from CTV in the United States and other countries. However, CTV still poses a great threat to the citrus industry, especially in the regions where the brown citrus aphid (Toxoptera citricida Kirk.), the most effective CTV vector, has become established (Yokomi et al., 1994).

Natural resistance to CTV occurs in some citrus relatives, including Atlantia ceylanica (Arn.) Oliv., Fortunella crassifolia Swingle, Poncirus trifoliata (L.) Raf., and Severinia buxifolia (Poir.) Ten. (Garnsey et al., 1987; Mestre et al., 1997; Yoshida, 1985). Among these species, the CTV resistance in P. trifoliata (the trifoliate orange) has attracted the most attention. Genetic analysis showed that the CTV resistance in $P$. trifoliata was controlled by a single dominant gene called Ctv (Fang et al., 1998; Gmitter et al., 1996; Yoshida, 1985).

Received for publication 20 Apr. 1998. Accepted for publication 11 Sept. 1998. This research was supported by the California Tristeza Research Coalition, and the Ira J. Condit Research Fund of the Univ. of California at Riverside. We gratefully thank Dr. Deborah M. Mathews and Professor Allan Dodds in the Dept. of Plant Pathology, UC Riverside, for providing antibodies and assistance in ELISA and RT-PCR tests. The cost of publishing this paper was defrayed in part by the payment of page charges. Under postal regulations, this paper therefore must be hereby marked advertisement solely to indicate this fact.

${ }^{1}$ To whom reprint requests should be addressed. Phone: (909) 787-4137; fax: (909) 787-4437; email: roose@citrus.ucr.edu
Although many CTV-resistant hybrids of citrus and trifoliate orange have been widely used as rootstocks for citrus trees, breeding a marketable CTV-resistant scion cultivar by crossing trifoliate orange with citrus has not been possible because undesirable traits of trifoliate orange remain after several generations of backcrossing with citrus. To overcome this problem, research toward isolating this resistance gene and then transforming it into CTV-susceptible citrus varieties is in progress in our laboratory and in Florida (F.G. Gmitter, personal communication). No genetic analysis has been reported for the CTV resistance in Atlantia ceylanica, Fortunella crassifolia, or Severinia buxifolia.

Recently, Garnsey et al. (1997) reported that some pummelo [Citrus maxima (Burm.) Merrill] cultivars were resistant to certain CTV isolates. This finding opens a possible way to breed CTV-resistant citrus scion cultivars by sexual hybridization.

To identify molecular markers linked to Ctv in trifoliate orange (Fang et al., 1998), we used two populations of 'Chandler' pummelo $x$ trifoliate orange, and 'Chandler' pummelo was found to be resistant to the CTV strain used. Because we developed many dominant and codominant molecular markers tightly linked to $C t v$ from trifoliate orange, we were able to study the inheritance of the CTV resistance present in 'Chandler' pummelo and to determine whether this resistance is controlled by a gene that is allelic with $C t v$. In this paper, we report our results.

\section{Materials and Methods}

Plant materials. Two populations segregating for CTV resistance, C. maxima cv. Chandler $\times$ P. trifoliata cv. Rubidoux, and $C$. maxima cv. Chandler $\times P$. trifoliata $\mathrm{cv}$. Webber Fawcett, were used. These populations had 58 and 26 progeny individuals, respectively. 'Rubidoux' is a small-flowered trifoliate orange, while 'Webber Fawcett' is a large-flowered one.

Determination of CTV resistance. Four buds from each progeny tree and their parent cultivars were grafted onto 'Pineapple' sweet orange rootstocks that were infected with CTV strain T-514 (a moderate strain in California). Three months after the buds grew, leaves from progeny shoots were harvested and their CTV resistance was evaluated by enzyme-linked immunosorbent assay (ELISA) according to Mathews etal.(1997). Leaves from the ELISAnegative progeny and those that gave ambiguous ELISA results were harvested again for ELISA tests after 6, 12, and 15 months. The absorbance at $405 \mathrm{~nm}$ was measured after 30 , 60 , and 90 min of substrate development at room temperature using an Emax plate reader and SoftMax software (Molecular Devices Corp., Menlo Park, Calif.). The sample was scored as susceptible to CTV if the absorbance value was 2.5 times that of the healthy control or higher. The CTV resistance of the parent cultivars was also evaluated by reverse transcriptase polymerase chain reaction (RT-PCR) according to Mathews et al. (1997).

$D N A$ extraction and polymerase chain reaction (PCR) amplification. Total DNA was extracted from leaves using $1.5 \%$ hexadecyltrimethylammonium bromide (CTAB) according to Fang et al. (1997). Random amplified polymorphic DNA (RAPD)-PCR amplification was carried out using reaction mixtures and temperature profiles described by Cheng and Roose (1995). Decamer primers were purchased from Operon Technologies, Alameda, Calif. Amplification products were resolved by electrophoresis through $1.8 \%$ agarose gel in $1 \times$ TBE buffer $(89 \mathrm{~mm}$ Tris-borate plus 2 mm EDTA, pH 8.2). The RAPD marker OpAD $08_{1100}$ was an 1100-bp product generated by primer OpAD08.

Molecular marker development. The molecular markers analyzed in this experiment were RAPD marker OpAD08 ${ }_{1100}$ and RFLP markers RfC19, RfE20, and RfZ16, all developed from RAPD markers by cloning PCR products. These markers originated from trifoliate orange, and were within 2 centiMorgans (cM) of $C t v$. The protocols for developing these markers were described previously (Fang et al., 1998).

\section{Results and Discussion}

CTV resistance in C. maxima cv. Chandler and its inheritance. All three parent cultivars, i.e., 'Chandler' pummelo, 'Rubidoux' trifoliate orange, and 'Webber Fawcett' trifoliate orange were found to be CTV-resistant after six ELISA and two RT-PCR tests over a period of 2 years. All 18 ELISA and six RT-PCR results were consistent. The CTV resistance in a trifoliate orange was controlled by a single dominant gene Ctv (Gmitter et al., 1996), and both trifoliate orange cultivars used herein were heterozygous for $C t v$ as shown from the genetic analysis in other populations. In $\mathrm{F}_{1}$ crosses that involved these trifoliate oranges, CTV resistance of progeny segregated 1:1 (resistant : susceptible) if the other parent was CTV-susceptible (Fang et al., 1998). However, the segregation of CTV resistance among progeny was consistent with a 3:1 ratio (resistant : susceptible) in both crosses used in this 
experiment (Table 1). These results suggested that 'Chandler' pummelo was also heterozygous for CTV resistance, and that this resistance was controlled by a single dominant gene designated as $C t v 2$.

Determination of the novelty of Ctv2. In order to determine whether $C t v 2$ was allelic to $C t v$, we proposed the following hypothesis. If these two genes were at the same locus, the markers closely linked to $C t v$ should be linked to $C t v 2$ as well. However, if they were different genes, linkage between $C t v 2$ and $C t v$ linked markers should not be observed. We used the data of four marker loci linked to $C t v$ to test this hypothesis (Table 2). OpAD08 ${ }_{1100}$ co-segregated with $C t v$ in a 65-progeny population (Deng et al., 1997). Our recent work (Fang et al., 1998) showed that this RAPD marker and RFLP markers RfC19, RfE20 and RfZ16 were within $2 \mathrm{cM}$ of $C t v$ in populations of 465 progeny. RfZ16 co-segregated with $C t v$, and no sequence homology for it was found in Citrus. This marker existed only in $P$. trifoliata and its hybrids, in which two codominant alleles were found. The other markers, RfC19 and OpAD08 ${ }_{1100}$, flanked Ctv at distances of 0.5 and $0.8 \mathrm{cM}$, respectively. The RAPD marker band and the progenitor bands of RFLP markers were amplified from trifoliate oranges. Since RfZ16 was the marker closest to $C t v$, we first used the genotype at this locus to predict the CTV resistance of progeny. All 42 progeny predicted to be CTV resistant by RfZ16 were resistant (Table 2). The other markers also correctly predicted resistant progeny, except for two progeny (type III) that were recombinants between RfC19 or RfE20 and RfZ16 or OpAD08 ${ }_{1100}$. However, of the 42 progeny predicted to be CTV-susceptible by the markers, only 20 were indeed susceptible. The remaining 22 progeny were CTV-resistant. 'Chandler' pummelo alleles at marker loci linked to $C t v$ were not associated with resistance in progeny that received the susceptible allele of $C t v$. These results clearly suggested that Ctv2 in 'Chandler' pummelo was not allelic with $C t v$ in trifoliate orange, although both were dominant genes. The genotypes at $C t v$ and $C t v 2$ for the $20 \mathrm{CTV}$-susceptible progeny were $\mathrm{rr}_{2} \mathrm{r}_{2}$; those for the 22 CTV-resistant progeny that were predicted to be susceptible by the markers should be $\mathrm{rr}_{2} \mathrm{r}_{2}$. For the $42 \mathrm{CTV}$-resistant progeny that had been predicted to be resistant by the markers, half should be $\operatorname{Rr} \mathrm{R}_{2} r_{2}$ and the other half $\operatorname{Rr}_{2} r_{2}$. Since we have not developed any markers linked to $C t v 2$, we were unable to differentiate between these two genotypes.

Garnsey et al. (1997) reported that the CTV resistance of some pummelo accessions depended on the CTV isolates tested. We do not know whether Ctv2 in 'Chandler' pummelo

Table 1. Segregation ratio for CTV resistance in two 'Chandler' pummelo $\mathrm{x}$ trifoliate orange populations.

\begin{tabular}{|c|c|c|c|c|c|}
\hline \multirow[b]{2}{*}{ Population } & \multirow[b]{2}{*}{ Male parent } & \multicolumn{2}{|c|}{ No. observed $^{2}$} & \multirow{2}{*}{$\begin{array}{c}\text { Expected } \\
\text { ratio }^{y}\end{array}$} & \multirow[b]{2}{*}{$\chi^{2}$} \\
\hline & & $\mathrm{R}$ & $\mathrm{S}$ & & \\
\hline 1 & P. trifoliata cv. Rubidoux & 43 & 15 & $3: 1$ & $0.034^{\mathrm{NS}}$ \\
\hline 2 & P. trifoliata cv. Webber Fawcett & 21 & 5 & $3: 1$ & $0.461^{\mathrm{Ns}}$ \\
\hline
\end{tabular}

${ }^{\mathrm{z}} \mathrm{R}=\mathrm{CTV}$-resistant, S = CTV-susceptible

${ }^{y}$ Expected ratio was 3:1 if the parent genotypes were either $\operatorname{Rr} \times \operatorname{Rr}$ or $r r R_{2} r_{2} \times \operatorname{Rrr}_{2} r_{2}$ and $C t v$ and $C t v 2$ showed independent assortment.

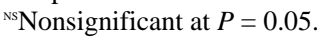

Table 2. Progeny phenotypes for CTV resistance and OpAD08 ${ }_{1100}$, and genotypes at RFLP marker loci. ${ }^{\mathrm{z}}$

\begin{tabular}{lcccccc}
\hline Marker types & No. progeny & CTV $^{y}$ & OpAD08 $_{1100}$ & RfC19 & RfZ16 & RfE20 \\
\hline I & 16 & + & + & bn & b & bd \\
II & 24 & + & + & bc & b & be \\
III & 2 & + & + & an & b & cd \\
IV & 14 & + & - & an & a & cd \\
V & 8 & + & - & ac & a & ce \\
VI & 12 & - & - & ac & a & ce \\
VII & 8 & - & - & an & a & cd \\
Chandler & & + & - & cn & none & de \\
Rubidoux & & + & + & ab & ab & bc \\
Webber Fawcett & & + & + & ab & ab & bw
\end{tabular}

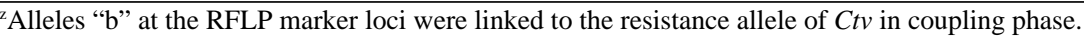

$\mathrm{y}_{+}=\mathrm{CTV}$-resistant, $-=$ CTV-susceptible

"Allele "c" in progeny corresponded to "c" or "w" from 'Rubidoux' and 'Webber Fawcett' trifoliate orange, respectively.

will provide durable resistance to a broad range of CTV strains. The next step of this research would test the resistance of $\mathrm{Ctv} 2$ against more CTV isolates, especially severe ones. Moreover, development of molecular markers linked to Ctv2 would allow us to select hybrids carrying the resistant allele of Ctv2 at the seedling stage, and to clone this gene using a map-based cloning strategy. Comparison of the sequences of two CTV resistance genes, Ctv and Ctv2, should provide a better understanding of the mechanisms of CTV resistance in citrus.

\section{Literature Cited}

Bar-Joseph, M., R. Marcus, and R.F. Lee. 1989. The continuous challenge of citrus tristeza virus control. Annu. Rev. Phytopathol. 27:291-316.

Cheng, F.S. and M.L. Roose. 1995. Origin and inheritance of dwarfing by the citrus rootstock Poncirus trifoliata 'Flying Dragon'. J. Amer. Soc. Hort. Sci. 120:286-291.

Deng, Z., S. Huang, S.Y. Xiao, and F.G. Gmitter. 1997. Development and characterization of SCAR markers linked to the citrus tristeza virus resistance gene from Poncirus trifoliata. Genome 40:697-704.

Fang, D.Q., C.T. Federici, and M.L. Roose. 1998. A high resolution linkage map of the citrus tristeza virus resistance gene region in Poncirus trifoliata (L.) Raf. Genetics 150:883-890.

Fang, D.Q., M.L. Roose, R.R. Krueger, and C.T. Federici. 1997. Fingerprinting trifoliate orange germplasm accessions with isozymes, RFLPs, and inter-simple sequence repeat markers. Theor. Appl. Genet. 95:211-219.
Garnsey, S.M., H.C. Barrett, and D.J. Hutchison. 1987. Identification of citrus tristeza virus resistance in citrus relatives and its potential applications. Phytophylactica 19:187-191.

Garnsey, S.M., H.J. Su, and M.C. Tsai. 1997. Differential susceptibility of pummelo and Swingle citrumelo to isolates of citrus tristeza virus, $p$. 138-146. In: Da Graca, J.V., P. Moreno and R.K. Yokomi (eds.). Proc. 13th Conf. Intl. Organ. Citrus Virologists, Univ. California Press, Riverside, Calif.

Gmitter, F.G., S.Y. Xiao, S. Huang, X.L. Hu, S.M. Garnsey, and Z. Deng. 1996. A localized linkage map of the citrus tristeza virus resistance gene region. Theor. Appl. Genet. 92:688-695.

Mathews, D.M., K. Riley, and J.A. Dodds. 1997. Comparison of detection methods for citrus tristeza virus in field trees during months of nonoptimal titer. Plant Dis. 81:525-529.

Mestre, P.F., M.J. Asins, J.A. Pina, and L. Navarro. 1997. Efficient search for new resistant genotypes to the citrus tristeza closterovirus in the orange subfamily Aurantioideae. Theor. Appl. Genet. 95:1282-1288.

Roistacher, C.N., D.G. Gumpf, J. A. Dodds, and R.F. Lee. 1991. The threat of 'the citrus killer'. Citrograph 76:4-11, 22.

Yokomi, R.K., R. Lastra, M.B. Stoetzel, V.D. Amsteegt, R.F. Lee, S.M. Garnsey, T.R. Gottwald, M.A. Rocha-Pena, and C.L. Niblett. 1994. Establishment of the brown citrus aphid (Homoptera:Aphididae) in Central America and the Caribbean Basin and transmission of citrus tristeza virus. J. Econ. Entomol. 87:1078-1085.

Yoshida, T. 1985. Inheritance of susceptibility to citrus tristeza virus in trifoliate orange (in Japanese with English summary). Bul. Fruit Tree Res. Sta. (Okitsu) B, No.12. p. 17-26. 